\title{
Time course of clinical and physiological effects of stimulation of the cerebellar surface in patients with spasticity
}

\author{
D. L. M c L E L L A N ${ }^{1}, M$. S E L W Y N, A N D I. S . C O O P E R \\ From the Institute of Neuroscience, St Barnabas Hospital, Bronx, New York, USA
}

S U M M A R Y A double-blind study of the short-term (12-48 hours) effects of cerebellar stimulation was performed on 11 selected patients with spasticity. Six of the patients had a good clinical long-term response to chronic stimulation, four had a moderate response, and one had no response. Each patient received stimulation for two periods of 24 hours and was off stimulation for two periods of 24 hours. The periods were randomised over four consecutive days. Neither the patients nor the observer could distinguish between the days on stimulation and the days off stimulation. Simple tests of function of the upper limbs during stimulation, measurements of $\mathrm{H}$ responses, tonic vibration responses, vibration-induced suppression of $\mathrm{H}$ responses, stretch responses, and co-contraction, showed no differences between the four days. These results are contrasted with the acute physiological changes seen in some patients during stimulation and also with the slow progressive improvement in clinical function that characterises the successful clinical response. It is suggested that lack of either acute or short-term changes in response to cerebellar stimulation does not predict the clinical outcome. If the strength of stimulation is changed, at least three days and preferably 10 days should be allowed for the effects to appear. The mechanisms responsible for the alleviation of spasticity are likely to be more complex than those mediating acute and reversible changes in reflex activity.

Several hundred patients with spasticity (mainly from cerebral palsy) have now been treated in various centres by chronic cerebellar stimulation (CCS), and there is increasing agreement that the therapeutic response-a generalised muscular relaxation-is clinically useful (Cooper et al., 1976; Cooper, 1977; Davis, 1977; Larson, 1977; Penn and Etzell, 1977). It has been found that the beneficial results of stimulation occasionally appear on the day that stimulation starts, but most patients do not begin to experience improvement until after several days, and a few not until after several months of continuous stimulation. In patients who respond well, the clinical effects are established by three to six months after starting CCS. On the other hand, immediate neurophysiological changes (in particular, changes in the amplitude of $\mathbf{H}$ responses and somatosensory

\footnotetext{
${ }^{1}$ Address for correspondence and reprint requests: Dr D. L. McLellan, Department of Neurology, Wessex Neurological Centre, Southampton General Hospital, Southampton, England.

Accepted 26 August 1977.
}

cerebral evoked potentials) have been reported to occur, with complex patterns of recovery lasting up to 30 minutes, after stimulation for as short a time as one minute (Upton and Cooper, 1976). The discrepancy between the speed and size of these reported physiological changes and, in most patients, the long latency and gradual progression of the clinical changes, raises questions about the relationship between the two phenomena. The present study was designed to see whether physiological changes persisted or were recruited over the course of several hours, and whether the clinical consequences of such changes could be identified.

\section{Methods}

TRIAL DESIGN, SELECTION OF PATIENTS, AND STRENGTHS OF STIMULATION

Patients with spasticity who could co-operate with the tests were selected. All gave informed consent to the trial. All but one of those selected had re- 
ported useful clinical improvement as a result of chronic cerebellar stimulation (Table 1). They were told that the strength of stimulation would change from day to day, that the investigator would not know the strength of stimulation, and that they would be asked to identify the two best days of the trial. Eight normal subjects aged 2036 years underwent motor function testing. They were not paired with the patients because the intention was to provide a qualitative rather than a quantitative comparison between normal and spastic subjects. Normative data for monosynaptic and vibration reflex testing were adopted from previous studies (McLellan, 1973).

The patients were being treated with the Avery stimulation apparatus. A radiofrequency (RF) signal was transmitted transcutaneously from antennae taped on the skin to two RF receivers permanently implanted beneath the skin. The receivers demodulated the RF signal to capacitatively coupled monophasic pulses lasting $0.5 \mathrm{~ms}$. at a frequency of 200 pulses per second. The receivers were connected by insulated wires to Avery eight-button electrode arrays on the superior surface of the left and right cerebellar hemispheres as described previously (Cooper et al., 1976). The location of the cathodes relative to the anodes was not standardised. The two receivers were activated alternately, changing every 60 seconds.

The geometric surface area of the cathodes in each electrode array was $32 \mathrm{~mm}^{2}$. The strength of the signal emitted by the stimulation apparatus was checked in the manner recommended by the manufacturer. A receiver was totally embedded in a perspex block. The top of the block was grooved to the shape of an antenna in such a way that the upper surface of the receiver was $3 \mathrm{~mm}$ below the floor of the groove. A standard calibration load of 1000 ohms and $0.022 \mu \mathrm{F}$ was wired across the output of the receiver and the stimulator was then calibrated according to the voltage drop across this load. It should be noted that this standard calibration load recommended by the manufacturer does not correspond to the characteristics of implanted electrodes, which have an impedance of 200 to 600 ohms (mean approximately 400 ohms, Valikai and Cooper, unpublished observations), and a capacitance of approximately $2 \mu \mathrm{F}$ to $10 \mathrm{~mA}$ impulses. As the output impedance of the receivers also varies from approximately 1000 to $1500 \mathrm{ohms}$ it is not possible to make more than a rough guess as to the current levels actually flowing at the electrodes. The patients' apparatus was calibrated to deliver up to a maximum of 10 volts across the calibration load, which would deliver a current at the electrodes of approximately 12 to $14 \mathrm{~mA}$, or a maximum charge density of approximately $0.20 \mu \mathrm{C} / \mathrm{mm}^{2} /$ pulse. Most patients did not feel any sensation from the stimulator at therapeutic dose levels. The thresholds for those who sensed stimulation are shown in Table 2.

Table 1 Clinical details of patients

\begin{tabular}{|c|c|c|c|c|c|c|}
\hline $\begin{array}{l}\text { Patient } \\
\text { number }\end{array}$ & $\begin{array}{l}\text { Age } \\
(y r)\end{array}$ & Sex & $\begin{array}{l}\text { Aetiology of } \\
\text { spasticity }\end{array}$ & $\begin{array}{l}\text { Duration } \\
\text { of CCS } \\
\text { (months) }\end{array}$ & $\begin{array}{l}\text { Long-term } \\
\text { clinical results }\end{array}$ & $\begin{array}{l}\text { Medication at } \\
\text { time of trial } \\
\text { (total daily dose) }\end{array}$ \\
\hline 1 & 31 & $\mathbf{M}$ & Cerebral palsy & 4 & $\begin{array}{l}\text { Good: hands freer, speech clearer, walking with } \\
\text { cane instead of walker }\end{array}$ & None \\
\hline 2 & 43 & $\mathbf{M}$ & Cerebral palsy & 14 & $\begin{array}{l}\text { Moderate: speech clearer, less tension in muscles } \\
\text { of trunk }\end{array}$ & Diazepam $15 \mathrm{mg}$. \\
\hline 3 & 18 & $\mathbf{M}$ & Cerebral palsy & 8 & $\begin{array}{l}\text { Good: arms no longer elevated, better hand control, } \\
\text { able to straighten legs }\end{array}$ & None \\
\hline 4 & 27 & $\mathbf{M}$ & Encephalitis & 17 & No change & None \\
\hline 5 & 30 & $\mathbf{F}$ & Cerebral palsy & 8 & $\begin{array}{l}\text { Good: legs looser, speech clearer, walks with } \\
\text { walker (previously chairbound) }\end{array}$ & None \\
\hline 6 & 24 & $\mathbf{M}$ & Head injury & 26 & Moderate: right hand looser, thinking clearer & Primidone $250 \mathrm{mg}$. \\
\hline 7 & 26 & $\mathbf{M}$ & Head injury & 5 & $\begin{array}{l}\text { Good: head more erect, talking and swallowing } \\
\text { better, improved sphincter control, left leg stronger. }\end{array}$ & None \\
\hline 8 & 35 & $\mathbf{M}$ & Cerebral palsy & 11 & $\begin{array}{l}\text { Good: thorax looser, right and bimanual dexterity } \\
\text { better, sits comfortably. }\end{array}$ & Diazepam $20 \mathrm{mg}$. \\
\hline 9 & 13 & $\mathbf{M}$ & Cerebral palsy & 21 & $\begin{array}{l}\text { Moderate: walking faster, better balance, sleep } \\
\text { undisturbed by involuntary movement. (Most of } \\
\text { improvement regressed after eight weeks). }\end{array}$ & None \\
\hline 10 & 16 & $\mathbf{F}$ & Cerebral palsy & 15 & $\begin{array}{l}\text { Moderate: more upright posture, better hand } \\
\text { control, left leg less stiff. }\end{array}$ & None \\
\hline 11 & 36 & $\mathbf{F}$ & Cerebral palsy & 23 & $\begin{array}{l}\text { Good: more upright posture, hips and neck } \\
\text { looser, speech clearer, less grimacing }\end{array}$ & $\begin{array}{l}\text { Diazepam } 15 \mathrm{mg} \text {. } \\
\text { Imipramine } 50 \mathrm{mg} \text {. }\end{array}$ \\
\hline
\end{tabular}


Table 2 Days of stimulation compared with patient's assessment $(A)$. There was no consistent correspondence between the patients' best days and the days on which they were stimulated. Strength of stimulation used during trial compared with threshold for production of abnormal sensations $(B)$. Only patients 5 and 8 were stimulated near their thresholds, and only patient 8 reported sensations during the trial

\begin{tabular}{|c|c|c|c|c|c|c|c|c|c|}
\hline \multirow{3}{*}{$\begin{array}{l}\text { Patient } \\
\text { number }\end{array}$} & \multicolumn{4}{|l|}{$A$} & \multicolumn{5}{|l|}{$B$} \\
\hline & \multicolumn{2}{|c|}{$\begin{array}{l}\text { Day numbers: } \\
\text { stimulation }\end{array}$} & \multicolumn{2}{|c|}{$\begin{array}{l}\text { Patient's two best } \\
\text { days in order of } \\
\text { preference }\end{array}$} & \multicolumn{2}{|c|}{$\begin{array}{l}\text { Strength of stimulation } \\
\text { (voltage across } 1000 \Omega) \\
\text { used clinically }\end{array}$} & \multicolumn{2}{|c|}{$\begin{array}{l}\text { Threshold for } \\
\text { sensation }\end{array}$} & \multirow[t]{2}{*}{$\begin{array}{l}\text { Side of best } \\
\text { clinical } \\
\text { response } \\
\text { to CCS }\end{array}$} \\
\hline & off & On & & & $R$ & $L$ & & $L$ & \\
\hline 1 & 3,4 & 1,2 & 4 & No preference & 11.2 & 11.0 & $>14$ & $>14$ & $=$ \\
\hline 2 & 1,2 & 3,4 & $2=4$ & & 10.0 & 10.0 & $>14$ & $>14$ & $=$ \\
\hline 3 & 1,2 & 3,4 & 3 & No preference & 9.2 & 8.8 & 11.2 & $>14$ & $\mathrm{~L}$ \\
\hline 4 & 1,3 & 2,4 & No pr & & 10.0 & 10.0 & $>14$ & 11.8 & None \\
\hline 5 & 2,3 & 1,4 & 2 & No preference & 11.2 & 11.4 & 10.3 & 9.8 & $\mathbf{R}$ \\
\hline 6 & 3,4 & 1,2 & 2 & 3 & 10.0 & 10.0 & $>14$ & 10.0 & $\mathbf{L}$ \\
\hline 7 & $2.4^{*}$ & 1,3 & 3 & No preference & 10.0 & 10.2 & $>14$ & $>14$ & $\mathbf{R}$ \\
\hline 8 & 2,3 & 1,4 & $3=4$ & & 8.8 & 4.2 & $>14$ & 4.2 & $\mathbf{R}$ \\
\hline 9 & 1,3 & 2,4 & No pr & & 10.0 & 10.0 & $>14$ & $>14$ & $=$ \\
\hline 10 & 2,3 & 1,4 & 3 & $1=2$ & 7.5 & 7.5 & $>14$ & $>14$ & $\mathbf{R}$ \\
\hline 11 & $3,4 \dagger$ & 1,2 & 1 & $2=3$ & 9.6 & 8.8 & 11.0 & $<14.0$ & $=$ \\
\hline
\end{tabular}

*Day 2 pads worn for two days with assessment on first day.

tDay 4 pads worn for two days with assessment on second day.

DOUBLE-BLIND TESTING

The stimulation was blocked by inserting aluminium foil between the antennae and the receiver under double-blind conditions. Squares measuring $64 \mathrm{~cm}^{2}$ were made from two pieces of broad opaque surgical tape by opposing the sticky surfaces, enclosing either a square of paper or two sheets of aluminium foil $0.15 \mathrm{~mm}$ thick. The contents of these pads could not be distinguished by their appearance or feel. Preliminary testing confirmed that a pad containing foil completely blocked transmission of the RF signal when interposed between antenna and receiver. The paper and tape combination did not affect the amplitude of the signal provided it was firmly applied. Two similar pads were placed in a series of numbered envelopes by a person unconnected with the trial. The envelopes were randomised as indicated in Table 2, and the key was left unopened until after all the results had been assessed at the end of the trial.

At 21.00 on the evening before the first day, the pads from the envelope marked "day 1" were taped on the skin over the implanted RF receivers, and the antennae were taped over the pads. At 21.00 the next night these pads were replaced by those from the next envelope. Nine patients completed this trial over four consecutive days but unavoidable delays occurred in two patients (Table 2) with interesting consequences.

On each day the patient was assessed as des- cribed below. The assessment of any one patient took place at the same time of day on each of the four days of the trial. The ambient temperature of the air-conditioned laboratory was $21^{\circ} \mathrm{C}\left(70^{\circ} \mathrm{F}\right)$ but skin temperature was not measured. The patient was asked to empty bowel and bladder before testing began. Regular medication was continued at its normal timing throughout the trial (Table 1).

\section{ASSESSMENT OF CLINICAL EFFECT}

The patient was asked how he was each day and his reply was recorded. Those parents who were staying with the patients during the trial were also questioned. On the last day the patient and his parents were asked to name in retrospect the two days on which there had been most benefit. On each day the investigator (DLMcL) performed a brief clinical assessment of muscle tone, tendon reflex excitability, and mobility, and recorded his impressions.

\section{QUANTITATIVE ASSESSMENT OF MOTOR FUNCTION Co-contraction index}

A light perspex splint was made to support the arm in a horizontal position with the forearm pronated. A pivot at the elbow allowed flexion and extension of the elbow. A linear potentiometer with a conducting plastic resistor was attached to the pivot to provide a record of the angle of the elbow. A sine wave target was then set up for the 
patient, requiring movement through $45^{\circ}$ at a frequency of $0.4 \mathrm{~Hz}$. The target appeared on a storage oscilloscope in front of the patient as a stationary display, upon which the signal from the goniometer was superimposed in the manner previously described (McLellan, 1977). After several practice sessions on the first day, the subjects were able to track this target with reasonable accuracy.

Surface electromyograms (EMG) were recorded from the skin overlying the biceps and triceps muscles. The skin was prepared by washing with $40 \%$ alcohol, abraiding with metal foil, and then rubbing with Hewlett Packard Redux paste. Circular Disa surface electrodes were attached to the skin with adhesive rings of $8 \mathrm{~mm}$ internal diameter. The electrode cavity was filled with Hewlett Packard Redux cream. It was found necessary to drill a small hole through the dome of each electrode to allow electrode cream to escape or to be injected into the electrode as necessary. The electrodes were placed $3 \mathrm{~mm}$ apart over the long axis of the muscle belly, and their location was marked with indelible ink to ensure identical placement each day. The patient was earthed (grounded) using a Velcro strap, containing a metal core, soaked in normal saline, and wrapped around the upper part of the forearm. The electrodes were connected by screened cable to a high-impedence $\left(2 \times 10^{7} \mathrm{ohm}\right)$ probe of a Grass amplifier (P511R) with the band-width set at $7 \mathrm{~Hz}$ to $2 \mathrm{kHz}$.

The goniometer output was fed to a Schmidt trigger adjusted to deliver a step voltage each time the elbow moved outside a prescribed arc or window. During voluntary movement the limits of the window were from $110^{\circ}$ to $155^{\circ}$ at the elbow joint. This window was just inside the arc of flexion-extension required to track the target. The step voltage was used to reset EMG integrators so that they summed biceps and triceps EMG only when the elbow moved within the window. A second trigger delivered a pulse at the same point in the window each time the elbow flexed; this pulse was used to trigger a CAT transient averager. The information thus available to the chart recorder is shown in Fig. 1. The amount of EMG in each phase-that is, flexion or extension-of movement across the window was indicated by the height of a spike on the chart recorder (Fig. 2). The mean of 15 cycles was measured. The amount of EMG during relaxation was divided by the amount of EMG during contraction and expressed as a percentage or "index of co-contraction" for each muscle (McLellan, 1977). Thirty cycles of movement were averaged by the CAT, the averaged signals being drawn out on an $X-Y$ plotter to show the phase relationships between joint angle, angular velocity, and the peak EMGs of the two muscles (Fig. 3).

To prevent the observer from detecting the operation of the patient's stimulator, a large artefact signal was added to the EMG input by a laboratory RF transmitter synchronised with the patient's stimulator. Such a signal would be summed with the EMG by the integrators. Therefore, immediately before measurements of co-contraction or stretch responses were made, the patient's stimulator and then the laboratory transmitter were turned off. As soon as the recording had been made, the transmitter and stimulator were turned on again. All other measurements were made with the patient's stimulator turned on.

\section{Angular velocity of voluntary movement of the elbow}

In addition to the tracking task, the patient was asked to flex and extend the elbow as quickly as possible across the window-that is, over an arc of $45^{\circ}$. To help the patient detect the limits of his movements the step signals from the window triggers were played through a loudspeaker. The audible "click" was kept fairly soft in order to

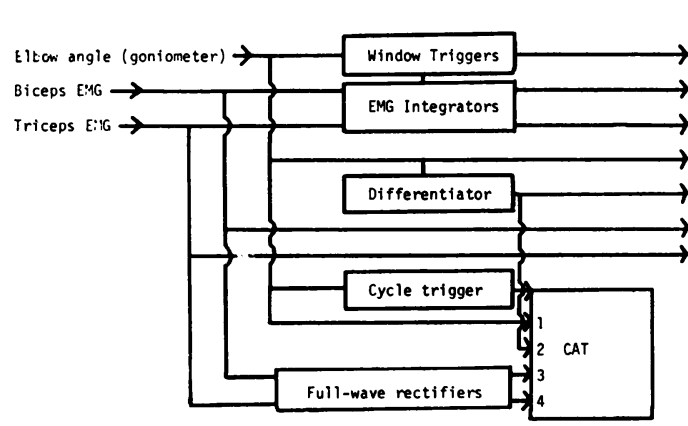

\section{CHART RECORDER}

. Limits of window

. Sum biceps EMG/phase

. Sum triceps EMG/phase

. Angle of elbow

. Angular velocity

. Biceps EMG

Triceps $E M T_{2}$

$X-Y$ PLOTTER

1. Elbow angle

2. Angular velocity of

3. Rectified biceps EMG average

. Rectified triceps EMG) cycle
Fig. 1 Circuit plan of apparatus used to assess voluntary movement, co-contraction, and stretch responses. Each cycle of movement contains two phases, a flexion phase and an extension phase. On the right of the figure is a summary of the information provided by the chart recorder and by the $X-Y$ plotter. 
$T \overrightarrow{R I G}$

IN T - B

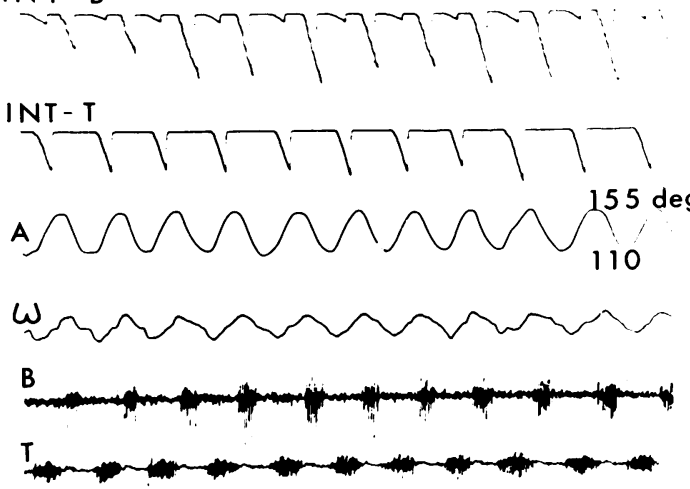

$\mathrm{Sec}$

NORMAL

(a)
TRIG

INT - B
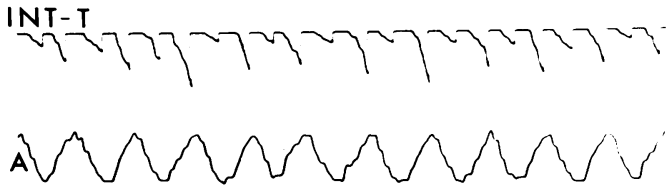

W

B

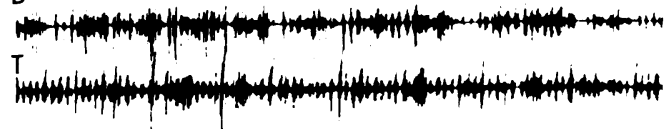

$\mathrm{Sec}$

SPASTIC

(b)

Fig. 2 Polygraphs of voluntary flexion-extension movement of the elbow in (a) a normal subject and (b) $a$ spastic patient tracking a sine wave target (target not shown). From bottom trace up: time marker, triceps EMG $(T)$, biceps $E M G(B)$, angular velocity at elbow $(W)$, angle at elbow $(A)$, integrated $T$ and integrated $B$ (depth of spike indicates amount of activity), and (top line) trigger output setting the window for integration.

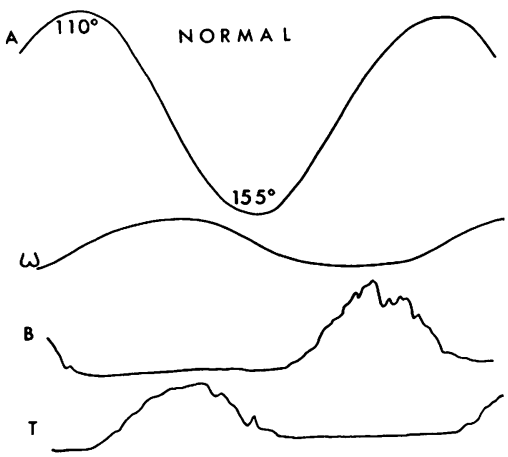

(a)

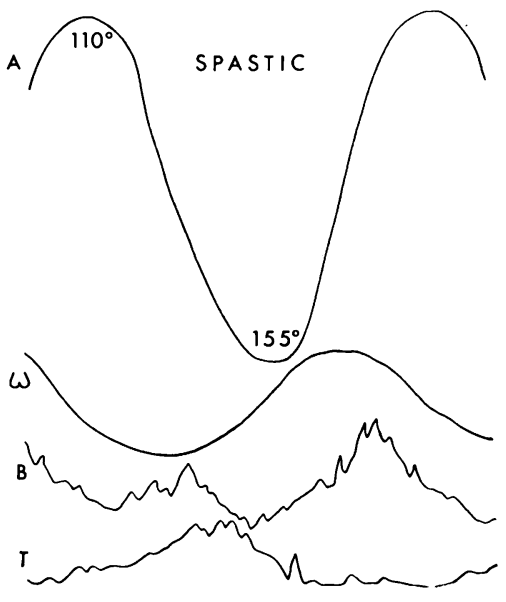

(b)

Fig. 3 A veraged record of 30 four-second epochs of elbow movement from (a) a normal subject and (b) a spastic patient. From bottom trace up: rectified triceps EMG $(T)$ and biceps EMG $(B)$, angular velocity at elbow $(W)$ and elbow angle $(A)$. The traces were recorded at different gains in order to identify the phase relationships between joint angle, angular velocity, and peak EMGs. 
avoid involuntary startle responses on the part of some patients. The mean frequency and the mean peak angular velocity (in both directions) of the first 10 cycles of this rapid movement were recorded.

The third test of elbow movement consisted of a rapid crossing of the window in one direction in response to a visual (displacement of oscilloscope trace) and auditory (click) signals delivered at intervals varying from 2-5 seconds after a preparatory command. Again, the mean peak angular velocity achieved during both flexion and extension were recorded.

\section{MEASUREMENT OF REFLEX RESPONSES}

Slow passive stretch responses (muscle tone): passive stretch index

Passive movements were performed manually by the same observer (DLMcL) using the same sinusoidal target as the patient had tracked. Similar precautions with respect to stimulus signals were taken. In an attempt to allow separation of the effects of speed of stretch from the effects of muscle length (Burke et al., 1971), stretching was performed at $0.4 \mathrm{~Hz}$ and at $0.8 \mathrm{~Hz}$ over two or three separate $45^{\circ}$ arcs of elbow displacement. The arcs chosen were $90-135^{\circ}, 110-155^{\circ}$, and $135-180^{\circ}$. Some limbs could not be tested throughout these ranges because of muscle contractures. If doubt arose about the source of surface EMG signals, a needle electrode was used to identify the contracting muscles and to confirm activation of the underlying muscle (for example, during shortening reactions). The amount of EMG generated during passive stretch was divided by the EMG generated during passive shortening to give the passive stretch index for each muscle.

\section{Isometric tonic vibration responses ( $T V R)$}

A strain gauge was connected to the arm rig in such a way as to prevent movement at the pivot and to measure the torque generated by an isometric muscle contraction. The angle of the elbow was set at $125^{\circ}$. The patient was asked to close his eyes and not to interfere voluntarily with any effects that vibration might have on the limb. A vibrator driven by an electric motor was applied in turn to the biceps and triceps muscles at approximately the junction of the muscle belly with its tendon. Vibration at $100 \mathrm{~Hz}$ (amplitude approximately $1 \mathrm{~mm}$ ) was continued for 20 seconds, and the torque was recorded. The means of four measurements from each muscle were calculated.

\section{$H$ responses}

The $\mathrm{H}$ response amplitude was recorded in the way recommended by Hugon (1973). The patient lay supine with the knees $60^{\circ}$ from full extension and the sole of the foot strapped against a firm board to give an angle at the ankle of $90^{\circ}$. Such a position was unsuitable for some spastic patients because it induced clonus. Two patients were too apprehensive about electrical stimulation to permit useful results to be obtained, and two patients could not tolerate the supine position. The latter patients were measured in the prone position. A firm rubber pad was placed under the ankle to maintain the desired angle of the knee, and the foot hung freely. The skin was prepared as above, and recording electrodes were attached over the soleus muscle in its midline and over the Achilles tendon. The grounded lead was placed between the proximal electrode and the knee. Separate stimulating electrodes were used. The anode was placed over the patella while the cathode was placed over the medial popliteal nerve in the popliteal fossa. The laboratory RF transmitter was synchronised with the patient's transmitter, and an artefact signal was fed into the EMG so that the observer could not tell whether the patient's receivers were being activated.

The maximal twitch response ( $M$ response) of the muscle was recorded. Thirty measurements of the peak-to-peak amplitude of the maximal $\mathrm{H}$ response (with or without an $\mathbf{M}$ response) were then recorded. Using stimuli that gave the largest $H$ response without an $M$ response, a limited exploration of the paired $\mathrm{H}$ recovery curve was performed. The same intensity of stimulus was used for the conditioning and the test shocks. The interval between conditioning and test shocks was set at $4 \mathrm{~ms}$ and increased progressively until an $\mathrm{H}$ response began to appear after the test shock, and this interval was recorded (" $\mathrm{H}$ second refractory period"). The interval was increased further until the amplitude of the test $\mathrm{H}$ equalled the amplitude of the conditioning $\mathrm{H}$ response (" $\mathrm{H}$ recovery period").

Finally, a vibrator (as above) was applied to the muscle belly $30 \mathrm{~mm}$ proximal to the proximal recording electrode, and, after vibration at $100 \mathrm{~Hz}$ for 20 seconds, 15 further measurements of maximal $H$ amplitude were made while vibration continued.

After the trial, seven of the patients turned their stimulator off for one hour. Groups of $10 \mathrm{H}$ responses with threshold $M$ responses, elicited at intervals of 8 seconds, were repeated every two to four minutes before, during, and for 20 minutes after one-minute bursts of bilateral cerebellar stimulation at the clinically effective voltage setting. The patients were unaware that stimulation had been given during this test. 
STATISTICAL ANALYSIS

The paired $t$ test was used to assess the significance of changes between daily trials. Mean data for all 11 patients are shown in the Tables but statistical analysis was performed also for the six patients whose clinical response had been good. For these six patients and for the whole group of 11 , the first day and the fourth day were compared to establish whether there was a practice effect. The first day on stimulation was compared with the first day off stimulation, and a similar comparison was made between the second days on and off stimulation. Both days on stimulation were compared with both days off stimulation. Finally, where stimulation had not changed during two consecutive days, the first day was compared with the second. Statistical analysis of those comparisons showed no significant differences even at the $10 \%$ level. When data from the individual patients were studied, striking differences were seen only in patient 11 .

\section{Results}

\section{CLINICAL OBSERVATIONS}

The observer was unable to distinguish days on from days off stimulation on the basis of clinical examination in any patient. In patient 8 , left cerebellar stimulation produced a buzzing sensation and hypaesthesia in the left side of his lower jaw. The patient had made an excellent clinical response to CCS. He reported the absence of buzzing sensations during the days off stimulation but was unable to detect any changes in function during the four days. The code for patient 6 was inadvertently broken on the fourth day when the observer received a telephone message from an EEG technician saying that the patient's stimulator did not appear to be working. The patients were unable consistently to identify the stimulation days on the basis of their performance. There may have been two exceptions. An extra day was unavoidably interposed within the trial of patients 7 and 11 . Thus, patient 7 continued wearing his day 2 pads for a further 24 hours after assessment. His mother later commented that on the second of these days, when no formal assessment was made and he had been off stimulation for $\mathbf{4 8}$ hours, his speech was slower and it was more difficult to dress him than usual because of stiffness of the shoulders. Patient 7 himself expressed no preference for any particular day, and in retrospect did not feel his performance had been noticeably worse on the day mentioned by his mother. Nevertheless, the time course of the alleged deterioration was consistent with his own account of the time it usually took for the effects of stimulation to wear off (Table 3). The final assessment of patient 11 was delayed for 24 hours. At that time after being off stimulation for three days, she reported that both legs were stiffer and harder to lift off the ground. She noted no change in speech or upper limbs. The changes in her legs were consistent with her own account of the habitual latency of the effects of stopping stimulation.

Table 3 Patients' opinions of timing and laterality of clinical response to CCS

\begin{tabular}{|c|c|c|c|c|c|c|}
\hline \multirow{2}{*}{$\begin{array}{l}\text { Patient } \\
\text { number }\end{array}$} & \multirow[t]{2}{*}{ Handedness } & \multirow{2}{*}{$\begin{array}{l}\text { Side of best } \\
\text { response }\end{array}$} & \multirow{2}{*}{$\begin{array}{l}\text { Long-term } \\
\text { clinical } \\
\text { response }\end{array}$} & \multicolumn{3}{|l|}{ Latency } \\
\hline & & & & $\begin{array}{l}\text { First therapeutic response } \\
\text { after start of } C C S\end{array}$ & $\begin{array}{l}\text { Clinical deterioration } \\
\text { after stopping } \\
\text { stimulation }\end{array}$ & $\begin{array}{l}\text { Clinical improvement } \\
\text { after restarting } \\
\text { stimulation }\end{array}$ \\
\hline 1 & $\mathbf{R}$ & $=$ & Good & 5 days: speech & None after $30 \mathrm{~min}$. & $?$ \\
\hline 2 & $\mathbf{R}$ & $=$ & Moderate & 4 days: speech & $12 \mathrm{hr}$ & $3 \mathrm{hr}$ \\
\hline 3 & $\mathbf{L}$ & $\mathbf{L}$ & Good & $2 \mathrm{hr}$ : shoulders freer & None after $1 \mathrm{hr}$ & $?$ \\
\hline 4 & $\mathbf{L} \rightarrow \mathbf{R}$ & & None & & No clinical response & \\
\hline 5 & $\mathbf{L}$ & $\mathbf{R}$ & Good & 2 days: feet freer & $24 \mathrm{hr}$ & 3 days \\
\hline 6 & $\mathbf{R} \rightarrow \mathbf{L}$ & $\mathbf{L}$ & Moderate & $\begin{array}{l}\text { Postsurgery but prestimulation } \\
\text { - hand freer; subsequent } \\
\text { change very gradual }\end{array}$ & None after 7 days & $?$ \\
\hline 7 & $\mathbf{R}$ & $\mathbf{R}$ & Good & $12 \mathrm{hr}:$ speech & $36 \mathrm{hr}$ & $2-3$ days \\
\hline 8 & $\mathbf{L}^{*}$ & $\mathbf{R}$ & Good & $\begin{array}{l}3 \text { wk: chest and shoulders } \\
\text { freer }\end{array}$ & 6 days & 14 days \\
\hline 9 & $\mathbf{R}$ & $=$ & Moderate & 3 wk: drooling and speech & $1 \mathrm{hr}$ & $12 \mathrm{hr}$ \\
\hline 10 & $\mathbf{R}$ & $\mathbf{R}$ & Moderate & 4 days: hand freer & 2 days & $4 \mathrm{hr}$ \\
\hline 11 & $\mathbf{L}$ & $=$ & Good & 6 wk: speech & 2 days & $6 \mathrm{hr}$ \\
\hline
\end{tabular}

*Dominant hand little impaired before treatment; $\rightarrow$ handedness changed by illness. 


\section{MOTOR FUNCTION}

Representative samples of the chart recordings from which EMG measurements were taken are shown in Fig. 2, and representative profiles of EMG activity averaged by the CAT in Fig. 3. The differences between normal and spastic records will be discussed in more detail in a report in preparation, but it would appear that the patient's performances were sufficiently abnormal for any marked improvement to have been detected by this method. No significant change occurred in any of the indices of motor function. The results obtained on and off stimulation are summarised in Table 4. This particular battery of tests corroborated the patients' subjective impressions of their overall performance but it remains to be seen whether it is more sensitive or more reliable than the patient's opinion as an index of change in motor function.

Considering the nature of their disability, the patients performed with reasonable consistency from one day to the next. The largest withinpatient change was less than $25 \%$ compared with substantial between-subject variations reflected in the large standard deviations of the grouped data (Table 4).

\section{SLOW PASSIVE STRETCH RESPONSES}

No significant changes occurred in the passive stretch index or in the phase relationship of the peak stretch response during the stretching cycle (Table 5).

The passive stretch index as defined above does not indicate resting EMG activity but is intended to measure the stretch-dependent component of the involuntary muscle contraction. A reduction of background activity unaccompanied by a reduction in the stretch-induced component would be missed by this technique. However, a similar method detected changes in spastic patients after an oral dose of the antispastic drug baclofen (McLellan, 1977).

Table 4 Tests of voluntary movement of upper limbs. Mean values $\pm S D$ shown for 11 patients and eight normal subjects

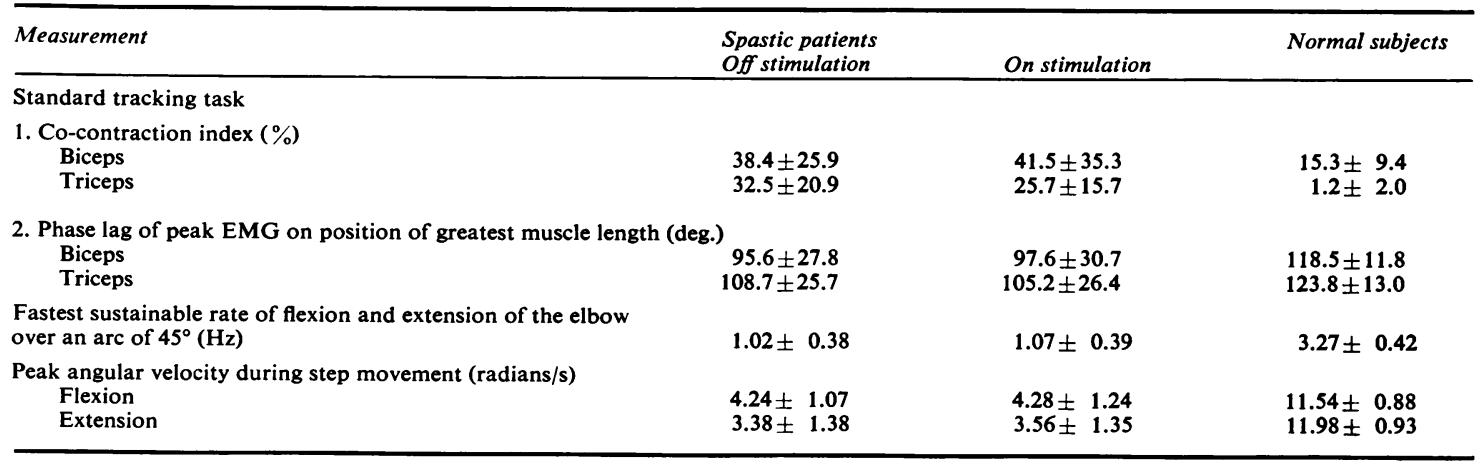

Table 5 Passive stretch responses to sinusoidal displacement in 11 patients: mean $\pm S D$. The passive stretch index is the ratio between the amount of EMG generated during passive stretch and the amount generated during passive shortening of the same muscle

\begin{tabular}{|c|c|c|c|c|}
\hline Measurement & $\begin{array}{l}\text { Slow stretch } \\
\text { Off stimulation }\end{array}$ & On stimulation & $\begin{array}{l}\text { Rapid stretch } \\
\text { Off stimulation }\end{array}$ & On stimulation \\
\hline $\begin{array}{l}\text { Passive stretch index } \\
\text { Biceps } 90-135^{\circ} \\
\text { Triceps }\end{array}$ & $\begin{array}{l}6.1 \pm 8.5 \\
1.6 \pm 2.2\end{array}$ & $\begin{array}{l}7.9 \pm 10.8 \\
2.2 \pm 4.8\end{array}$ & $\begin{array}{l}6.3 \pm 8.5 \\
2.1 \pm 2.6\end{array}$ & $\begin{array}{l}8.2 \pm 12.5 \\
3.3 \pm 5.4\end{array}$ \\
\hline $\begin{array}{l}\text { Biceps } 135-180^{\circ} \\
\text { Triceps }\end{array}$ & $\begin{array}{l}6.5 \pm 8.1 \\
2.7 \pm 6.6\end{array}$ & $\begin{array}{l}8.6 \pm 12.7 \\
2.5 \pm 6.6\end{array}$ & $\begin{array}{l}7.1 \pm 9.5 \\
3.4 \pm 7.2\end{array}$ & $\begin{array}{r}11.8 \pm 12.2 \\
4.0 \pm 7.8\end{array}$ \\
\hline $\begin{array}{l}\text { Phase lead of peak co } \\
\text { position of maximum } \\
\text { Biceps } 90-135^{\circ} \\
\text { Triceps }\end{array}$ & $\begin{array}{r}57.7 \pm 20.8 \\
110.1 \pm 55.3\end{array}$ & $\begin{array}{l}55.3 \pm 22.9 \\
68.8 \pm 20.4\end{array}$ & $\begin{array}{l}67.9 \pm 30.9 \\
74.2 \pm 36.0\end{array}$ & $\begin{array}{l}60.7 \pm 17.5 \\
48.5 \pm 16.2\end{array}$ \\
\hline $\begin{array}{l}\text { Biceps } 135-180^{\circ} \\
\text { Triceps }\end{array}$ & $\begin{array}{l}67.0 \pm 35.4 \\
41.0 \pm 8.5\end{array}$ & $\begin{array}{l}67.0 \pm 22.3 \\
51.0 \pm 7.9\end{array}$ & $\begin{array}{l}72.1 \pm 33.1 \\
52.6 \pm 39.3\end{array}$ & $\begin{array}{l}71.1 \pm 28.4 \\
50.2 \pm 28.1\end{array}$ \\
\hline
\end{tabular}


H AND ISOMETRIC TONIC VIBRATION REFLEXES

Despite the acute changes that have been reported to occur in response to short bursts of cerebellar stimulation, no statistically significant changes were seen over the few days of observation (Table 6). The change that approached nearest to statistical significance was the lengthening of the $\mathrm{H}$ refractory period. Inspection of the data indicated that one patient (11) showed a striking shortening of her refractory period when stimulation stopped. Moreover the effects of muscle vibration on the $H$ response were smaller when she was off stimulation (Table 7). The strength of the TVR did not change.

Table 6 Monosynaptic and tonic vibration reflexes: mean values $\pm 1 S D$

\begin{tabular}{|c|c|c|c|}
\hline \multirow[t]{2}{*}{ Measurement } & \multicolumn{2}{|c|}{ Spastic patients } & \multirow{2}{*}{$\begin{array}{l}\text {-Normal } \\
\text { subjects }\end{array}$} \\
\hline & $\begin{array}{l}\text { Off } \\
\text { stimulation }\end{array}$ & $\begin{array}{l}\text { On } \\
\text { stimulation }\end{array}$ & \\
\hline $\mathbf{H} / \mathbf{M} \%$ & $63.3 \pm 15.0$ & $61.2 \pm 13.6$ & $22.4 \pm 9.2$ \\
\hline \multicolumn{4}{|l|}{$\mathbf{H}$ during vibration } \\
\hline 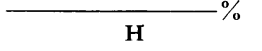 & $65.1 \pm 27.3$ & $65.8 \pm 27.6$ & $\left(32^{*}\right)$ \\
\hline $\mathrm{H}$ refractory period (ms) & $7.3 \pm 9.37$ & $16.8 \pm 15.2$ & $58.6 \pm 11.8$ \\
\hline $\begin{array}{l}\text { Torque produced by } \\
\text { TVR: biceps }(\mathrm{N} / \mathrm{m}) \\
\text { triceps }(\mathrm{N} / \mathrm{m})\end{array}$ & $\begin{array}{l}0.24 \text { 土 } 0.21 \\
0.24 \pm 0.31\end{array}$ & $\begin{array}{l}0.24 \pm 0.17 \\
0.24 \pm 0.26\end{array}$ & $\begin{array}{l}0.93 \pm 0.40 \\
0.46 \pm 0.28\end{array}$ \\
\hline
\end{tabular}

*Mean value for normal subjects aged 20-30 years, from Delwaide (1973).

Table 7 Reflex testing in patient 11 (means of right and left limbs)

\begin{tabular}{|c|c|c|c|c|c|}
\hline \multirow{2}{*}{ Measurement } & \multicolumn{5}{|c|}{ Day of trial } \\
\hline & $\begin{array}{l}1 \\
O n\end{array}$ & $\begin{array}{l}2 \\
O n\end{array}$ & $\begin{array}{l}3 \\
\text { Off }\end{array}$ & $\stackrel{4}{O f f}$ & $\begin{array}{l}5 \\
\text { Off }\end{array}$ \\
\hline $\mathrm{H} / \mathrm{M} \%$ & 49.7 & 58.7 & 61.8 & & 58.3 \\
\hline $\mathbf{H}$ vibration & & & & & \\
\hline$-\mathrm{H}$ & 25.2 & 26.0 & 23.2 & & 55.4 \\
\hline $\begin{array}{l}\text { H refractory } \\
\text { period (ms) }\end{array}$ & 25 & 36 & 4 & & 4 \\
\hline $\begin{array}{l}\text { H recovery } \\
\text { period (ms) }\end{array}$ & 200 & 252 & 242 & & 207 \\
\hline
\end{tabular}

ACUTE CHANGES IN H RESPONSES AFTER ONE-MINUTE BURSTS OF CEREBELLAR STIMULATION

Acute changes in $\mathrm{H}$ response amplitude induced by one-minute bursts of cerebellar stimulation in this group of patients were disappointingly small and variable. Two patients had previously been studied with positive results immediately after implantation of the electrodes (Upton and Cooper,
1976) but these findings could not be replicated during the present study some six months later. These studies will be described in detail in a later report. When the results were analysed using Student's $t$ test, none of these seven patients showed statistically significant acute changes of $H$ response amplitude. Somatosensory evoked potentials were not recorded.

\section{Discussion}

In the face of the negative findings described in this paper, we wish to emphasise that most of these patients had derived definite clinical benefit from CCS as in Table 1. They had been in a stable state for several years before starting CCS so that such improvements were most unlikely to have been placebo effects. It is our purpose here to point out that worthwhile clinical improvements were not reflected in acute or short-term on-off changes in $\mathrm{H}$ responses or by short-term changes in tonic vibration responses, stretch responses, or voluntary movements. Such measurements would not, therefore, have predicted the effects of therapy, nor could they be used to es:ablish effecttive strengths of stimulation. The patients who had responded well to CCS had usually noticed improvement within the first three weeks of stimulation. The latencies of clinical response reported in this paper are representative of patients treated by CCS, although an exceptional patient may show a much faster response than this, with a time course similar to that of acute reflex changes (Upton and Cooper, 1977). The therapeutic effects of stimulation are probably not a consequence of immediate, measurable reflex changes. However, as shown in Table 8, a gradual clinical improvement itself may be accompanied by progressive reflex changes. Table 8 illustrates a series of open observations in a girl aged 18 years during her first three months of cerebellar stimulation while moderate improvement was taking place. Acute changes induced in the same patient by turning the stimulator on and off are shown in Fig. 4.

Despite this dissociation between the occurrence of acute and chronic changes, both the clinical and the acute physiological effects of CCS appear to be more pronounced in the dominant than in the non-dominant limbs (Tables 3 and 8 , and Upton and Cooper, 1976). Of 200 consecutive patients with cerebral palsy examined at this Institute, $47 \%$ were left handed. Most patients with cerebral palsy show a considerable functional difference between the dominant and nondominant sides whether on the left side or on the right, accompanied by clear neurological signs of 
Table 8 Measurement of $H$ responses during the first 10 weeks of left sided CCS in a girl aged 18 years (see also Fig. 4), showing progressive reduction in the excitability of the responses in both legs after operation on 10 January 1977

\begin{tabular}{|c|c|c|c|c|c|c|c|c|}
\hline \multirow{3}{*}{ Date } & \multirow{2}{*}{\multicolumn{2}{|c|}{$H / M_{\circ}^{\circ}$}} & & & \multicolumn{4}{|c|}{ Paired $H$ responses } \\
\hline & & & $H v i$ & & \multicolumn{2}{|c|}{ Refractory period ( $m s)$} & \multicolumn{2}{|c|}{ Recovery time (ms) } \\
\hline & $R$ & $L$ & $R$ & $L$ & $R$ & $L$ & $R$ & $L$ \\
\hline 6 Jan 77 Pre-op & 81 & 75 & \multicolumn{2}{|c|}{ Not tested } & 6 & 4 & 80 & 140 \\
\hline $20 \mathrm{Jan}$ & 95 & 85 & 100 & 97 & 4 & 10 & 140 & 160 \\
\hline$* 17 \mathrm{Feb}$ & 72 & 45 & \multicolumn{2}{|c|}{ Not tested } & 4 & 10 & 105 & 150 \\
\hline $23 \mathrm{Mar}$ & 51 & 41 & 70 & 29 & 4 & 4 & 245 & 210 \\
\hline
\end{tabular}

*Clinical improvement first apparent at five weeks.

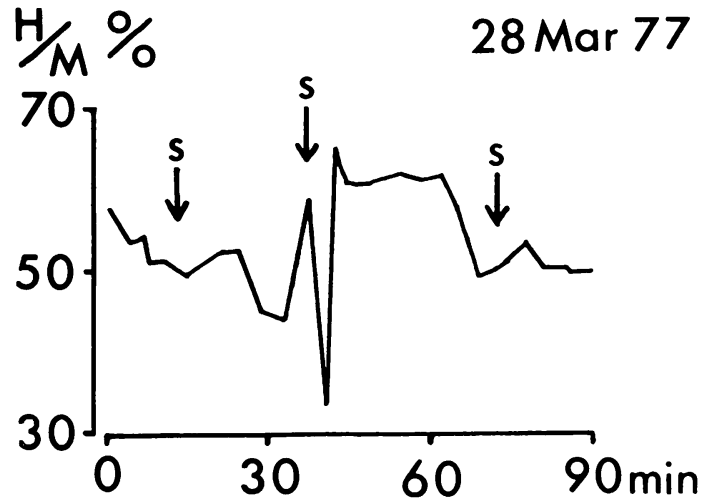

Fig. 4 Serial measurements of $H / M$ ratio during one afternoon in patient whose responses are shown in Table 8. One minute's ipsilateral stimulation of anterior and posterior cerebellum at the clinically effective voltage ( $9 \mathrm{~V}$ across $1000 \mathrm{ohms}$ ) given at $\mathrm{S}$. The response to stimulation is inconsistent. CCS was discontinued for one hour before this recording started.

asymmetrical brain damage. Thus the apparent superiority of the "dominant" cerebellar hemisphere in its response to stimulation may indicate simply that the less severely affected elements in a malfunctioning motor system are capable of the greatest recovery. However, it seems that when the dominant limb already has near normal function, further improvement is relatively more difficult to achieve (Table 3 ). If the axial muscles were to show a similar pattern of response, the development of scoliosis could be altered by CCS. Bilateral reduction in axial muscle tone would probably retard the development of scoliosis but an increase in the discrepancy between the good side and the bad side could accelerate it. So far, there has been no evidence that CCS has affected scoliosis (Cooper et al., 1976).

In view of the fact that the patients reported here did not feel subjectively improved on their days on stimulation, our failure to show improvement in the pattern and speed of movement probably means that no improvement occurred during the trial. It is well known that the greatest overflow into inappropriate contraction of spastic muscles occurs during vigorous voluntary effort. In addition, there may be fundamental physiological differences between a simple, purely voluntary movement and semivoluntary movements such as walking, or the maintenance of posture. The clinical reports of the effects of CCS suggest that some of the principal improvement is in posture and "general muscle relaxation", neither of which was monitored in the present study because of the obvious practical difficulties.

A secondary goal of this study was to perfect a method of "blinding" both patient and observer to the operation of the stimulator.

The method of aluminium foil shielding would not be suitable for longer-term investigation because the patients would notice that their batteries discharged more quickly. An EEG recording and possibly radio interference could provide additional clues. The most effective method of "blinding" the observations would be to have a switch located on the wires between receiver and electrode that could be operated externally. It would also be necessary to render the stimulator controls inaccessible to the patients, who might otherwise succumb to the temptation to increase the voltage of stimulation to the level at which they would anticipate headache. When comparing different strengths of stimulation, it is not possible with present apparatus to know precisely what current is flowing into the electrodes, or to test whether the threshold for stimulation of the cerebellum itself has altered.

Little change is likely to have occurred over four days but serious errors could arise in assessing the results of chronic stimulation. 
We suggest that the implanted apparatus should be modified to allow accurate monitoring of electrode current. We have not been able to record potentials over contralateral sensorimotor cortex evoked by cerebellar stimuli, probably because of the size of field and muscle artefact. The development of improved methods of amplification and artefact subtraction, or possibly the measurement of evoked magnetic fields (Williamson et al., 1977) could enable such potentials to be detected. This could be a most valuable tool in monitoring the progress of CCS patients. Until such measurement is possible, acute changes in monosynaptic reflex responses or in somatosensory or visual evoked responses may be used to confirm activation of the cerebellum in some patients (Upton and Cooper, 1977).

A review of the physiological mechanisms involved in CCS is beyond the scope of this paper. The initial concept of specific activation of Purkinje cells has been modified by the discovery that many other neurones respond to stimulation of the cerebellar surface. Several alternative or additional mechanisms have been suggested such as antidromic activation of the ascending reticular function or progressive and sustained adaption of neurotransmitter release (Bantli et al., 1976; Wood et al., 1977a, b). The difference in latency between immediate physiological changes and slow progressive clinical changes suggests that different mechanisms underlie the two phenomena. Clinical studies which employ techniques similar to those described here should allow at least three days and preferably 10 days for the effects of a change in the strength of stimulation to appear.

We wish to thank the patients for their cooperation, and $\mathrm{Dr} T$. Cullinan for his helpful criticism of this paper. We are grateful to the Hearst Foundation, United Cerebral Palsy of New York, and Ciba-Geigy Ltd. for financial support.

\section{References}

Bantli, H., Bloedel, J. R., and Tolbot, D. L. (1976). Activation of neurones in the cerebellar nuclei and ascending reticular formation by stimulation of the cerebellar surface. Journal of Neurosurgery, 45, 539-554.

Burke, D., Andrews, C. J., and Gillies, J. D. (1971). The reflex response to sinusoidal stretching in spastic man. Brain, 94, 455-470.

Cooper, I. S. (1977). Safety and efficiency of chronic cerebellar stimulation. In Proceedings of the Sym- posium on Safety and Clinical Efficacy of Implanted Neuroaugmentive Devices. AAMI: San Francisco.

Cooper, I. S., Riklan, M., Amin, I., Waltz, J., and Cullinan, T. (1976). Chronic cerebellar stimulation in cerebral palsy. Neurology (Minneapolis), 26, 8, 744-753.

Davis, R. (1977). Clinical effects of cerebellar stimulation. In Proceedings of the Symposium on Safety and Clinical Efficacy of Implanted Neuroaugmentive Devices. AAMI: San Francisco.

Delwaide, P. J. (1973). Human monosynaptic reflexes and presynaptic inhibition. In New Developments in Electromyography and Clinical Neurophysiology. Vol. 3, pp. 508-522. Edited by J. E. Desmedt. Karger: Basel.

Hugon, M. (1973). Methodology of the Hoffman reflex in man. In New Developments in Electromyography and Clinical Neurophysiology. Vol. 3, pp. 277-293. Edited by J. E. Desmedt. Karger: Basel.

Larson, S. J. (1977). Effects of cerebellar stimulation. In Proceedings of the Symposium on Safety and Clinical Efficacy of Implanted Neuroaugmentive Devices. AAMI: San Francisco.

McLellan, D. L. (1973). Effect of baclofen upon monosynaptic and tonic vibration reflexes in patients with spasticity. Journal of Neurology, Neurosurgery, and Psychiatry, 36, 555-560.

McLellan, D. L. (1977). Co-contraction and stretch reflexes in spasticity during treatment with baclofen. Journal of Neurology, Neurosurgery, and Psychiatry, 40, 30-38.

Penn, R. D., and Etzel, M. L. (1977). Chronic cerebellar stimulation and developmental reflexes. Journal of Neurosurgery, 46, 506-511.

Upton, A. R. M., and Cooper, I. S. (1976). Someco neurophysiological effects of cerebellar stimulation? in man. Canadian Journal of Neurological Science, $3,237-254$.

Upton, A. R. M., and Cooper, I. S. (1977). Physiological aspects of cerebellar stimulation in man. In Plenary Session of the Cushing Society. Toronto, April 25.

Williamson, S. J., Kaufman, L., and Brenner, D. (1977). Biomagnetism. Chapter 8 in Superconductor applications: SQUIDS and machines. Edited by B. B. Schwartz and S. Fones. Plenum Publishing Corporation: New York.

Wood, J. H., Glaeser, B. S., Hare, T. A., Sode, J., Brooks, B. R., and Van Buren, J. M. (1977a). Cerebrospinal fluid GABA reductions in seizure patients evoked by cerebellar surface stimulation. Journal of Neurosurgery, 47, 582-589.

Wood, J. H., Lake, C. R., Zeigler, M. G., Sode, J., Brooks, B. R., and Van Buren, J. M. (1977b). Cerebrospinal fluid norepinephrine alterations during electrical stimulation of cerebellar and cerebral surfaces in epileptic patients. Neurology (Minneapolis), 27, 716-724. 